Article

\title{
Asperflavin, an Anti-Inflammatory Compound Produced by a Marine-Derived Fungus, Eurotium amstelodami
}

\author{
Xiudong Yang ${ }^{1,2}$, Min-Cheol Kang ${ }^{2}$, Yong $\mathrm{Li}^{3}{ }^{3}$, Eun-A. Kim ${ }^{2}$, Sung-Myung Kang ${ }^{4}$ \\ and You-Jin Jeon 2,5,* \\ 1 College of Chemical and Pharmaceutical Engineering, Jilin Institute of Chemical Technology, Jilin 132022, \\ China; yangwt_1981@163.com \\ 2 Department of Marine Life Science, Jeju National University, Jeju 690-756, Korea; \\ networksun@naver.com (M.-C.K.); yellow6798@hanmail.net (E.-A.K.) \\ 3 College of Pharmacy Science, Changchun University of Traditional Chinese Medicine, Changchun 130017, \\ China; donaikun@163.com \\ 4 Pediatric Oncology Experimental Therapeutics Investigators Consortium (POETIC) Laboratory for \\ Pre-Clinical and Drug Discovery Studies, University of Calgary, Calgary, AB T2N1N4, Canada; \\ tjdaud81@gmail.com \\ 5 Marine and Environmental Research Institute, Jeju National University, Jeju 695-814, Korea \\ * Correspondence: youjin2014@gmail.com; Tel.: +82-64-754-3475
}

Received: 21 September 2017; Accepted: 24 October 2017; Published: 29 October 2017

\begin{abstract}
In the present study, 16 marine-derived fungi were isolated from four types of marine materials including float, algae, animals and drift woods along with the coast of Jeju Island, Korea and evaluated for anti-inflammatory effects in lipopolysaccharide (LPS)-stimulated RAW 24.7 cells. The broth and mycelium extracts from the 16 fungi were prepared and the broth extract (BE) of Eurotium amstelodami (015-2) inhibited nitric oxide (NO) production in LPS-stimulated RAW 264.7 cells without cytotoxicity. By further bioassay-guided isolation, three compounds including asperflavin, neoechinulin A and preechinulin were successfully isolated from the BE of E. amstelodami. It was revealed that asperflavin showed no cytotoxicity up to $200 \mu \mathrm{M}$ and significantly inhibited LPS-induced NO and PGE2 production in a dose-dependent manner. In the western blot results, asperflavin suppressed only inducible NOS (iNOS), but COX-2 were slightly down-regulated. Asperflavin was also observed to inhibit the production of pro-inflammatory cytokines including TNF- $\alpha$, IL-1 $\beta$, and IL-6. In conclusion, this study reports a potential use of asperflavin isolated from a marine fungus, E. amstelodami as an anti-inflammatory agent via suppression of iNOS and pro-inflammatory cytokines as well as no cytotoxicity.
\end{abstract}

Keywords: asperflavin; marine fungus; Anti-inflammation; Eurotium amstelodami; NO production

\section{Introduction}

As marine microorganisms have proved their value as sources of bioactive compounds, they have attracted more attention due to their diverse living environment. In the past few decades, marine-derived fungi have been proven to be an important source of novel and bioactive natural products. So far, thousands of secondary metabolites from marine-derived fungi have been reported [1]. Metabolites with unique structural features have been found in marine fungi that greatly differ from those found in terrestrial counterparts. Furthermore, most of these compounds were found to possess antioxidant, antimicrobial, anti-cancer and anti-inflammatory effects in vitro or in vivo [2]. The majority of the isolated compounds (almost 50\%) belonged to polyketides and their isoprene hybrids, followed by alkaloids, terpenes, and peptides, which contributed $14-20 \%$. These new 
compounds were produced mostly from members of the fungal genera Penicillium and Aspergillus. Representatives of other genera including Acremonium, Emericella, Epicoccum, Exophiala, Paraphaeospaeria, Phomopsis, and Halarosellinia were less common [3].

Inflammation is a beneficial host response to foreign challenge or tissue injury that ultimately leads to the restoration of tissue structure and function [4]. However, prolonged inflammation can be harmful, leading to the pathogenesis of many diseases. Macrophages play an important role in host defenses against noxious substances and are involved in a variety of disease processes including autoimmune diseases, inflammatory disorders and infections [5]. They are potent secretory cells that release an array of mediators, including pro-inflammatory and cytotoxic cytokines as well as growth factors, bioactive lipids, hydrolytic enzymes, reactive oxygen intermediates, and nitric oxide (NO), all of which have been implicated in the pathogenesis of tissue injury [6,7]. Macrophages are activated by IFN- $\gamma$, pro-inflammatory cytokines and lipopolysaccharide (LPS). Activated macrophages play an important role in inflammatory diseases via production of cytokines, including interleukin-1 $\beta$ (IL-1 $\beta)$, tumor necrosis factor-alpha (TNF- $\alpha$ ), and IL-6 [8-10]. These inflammatory cytokines and mediators are essential for host survival following infection and are also required for the repair of tissue injuries [11,12]. Over-expression of the inflammatory mediators in macrophage is involved in many inflammations related diseases, such as rheumatoid arthritis, atherosclerosis, chronic hepatitis and pulmonary fibrosis [13]. Thus, inhibition of these inflammatory mediators is an important strategy in the treatment of inflammatory diseases.

In mammalian cells, NO is synthesized by three different isoforms of nitric oxide synthase (NOS): endothelial NOS (eNOS), neuronal NOS (nNOS) and iNOS. Importantly, iNOS is highly expressed in LPS-activated macrophages and contributes to the pathogenesis of septic shock $[14,15]$. Cyclooxygenase (COX) is an enzyme that catalyzes the conversion of arachidonic acid to prostaglandin $\mathrm{H} 2$, a precursor for a variety of biologically active mediators, such as prostaglandin E2 ( $\left.\mathrm{PGE}_{2}\right)$, prostacyclin and thromboxane $A_{2}$ [16,17]. Two isoforms of COX have been found: COX-1 and COX-2. COX-2 is induced by several stimuli, and is responsible for the production of large amounts of pro-inflammatory prostaglandins at the inflammatory site [7,18]. PGE2 is derived from the catalyzation of arachidonic acid by COX-2 pathway. Therefore, NO production via iNOS pathway or $\mathrm{PEG}_{2}$ production via COX-2 pathway is the two key pathways in inflammatory processes.

In this study, as a part of our on-going screening program to evaluate the anti-inflammatory potential of marine-derived natural compounds, we investigated anti-inflammatory effects of broth and mycelium extracts of 16 marine fungi in RAW 264.7 cells. Furthermore, active compounds from the selected fungus were isolated and identified, and finally the anti-inflammatory effects and potential mechanisms of the isolated compounds were also evaluated in LPS-stimulated RAW264.7 cells.

\section{Results}

\subsection{Culture and Isolation of Marine-Derived Fungi}

A total of 16 fungi were isolated from four types of samples including algae, animals, floats and drift woods and then their strains were identified (Table 1). These fungal strains belong to four genera and two of them were unidentified. Most of the identified strains belong to the genus of Penicillium (7 strains), and three of them were from the genus of Aspergillus. The other species were of the genus of Eurotium and Fusarium. Although some of the isolated strains were the same, they were isolated from different hosts in the sea. 
Table 1. Fungal strains isolated from marine resources.

\begin{tabular}{lccc}
\hline \multicolumn{1}{c}{ Name } & Host & Similarity (\%) & No. \\
\hline Unkown & Float & & $003-2$ \\
Unkown & Drift wood & & $007-1$ \\
Aspergillus clavatus & Drift wood & 100 & $045-3$ \\
Aspergillus tamarii & Float & 98 & $002-2$ \\
Aspergillus sp. & Alga & 98 & $063-3$ \\
Eurotium amstelodami & Animal & 100 & $015-2$ \\
Eurotium amstelodami & Float & 100 & $045-1$ \\
Fusarium oxysporum & Alga & 100 & $069-1$ \\
Fusarium sp. & Alga & 100 & $050-1$ \\
Penicillium chrysogenum & Alga & 100 & $010-1$ \\
Penicillium chrysogenum & Float & 99 & $079-2$ \\
Penicillium crustosum & Alga & 100 & $066-2$ \\
Penicillium janthinellum & Animal & 96 & $053-1$ \\
Penicillium oxalicum & Alga & 100 & $075-1$ \\
Penicillium sp. & Alga & 99 & $079-1$ \\
Penicillium sp. & Alga & 100 & $079-3$ \\
\hline
\end{tabular}

For evaluation of the biological activities of the extract from the fungal strains, all the strains were cultured in the flask with $100 \mathrm{~mL}$ of liquid culture medium. After several days, the fungal strains were further extracted to give broth extract (BE) and mycelium extract (ME) from broth and mycelium of the cultured strains. The BE and ME from each strain were checked on TLC to observe the profile of chemical composition (date not shown).

\subsection{Cell Viability and NO Production Inhibitory Effects of the Extracts from Marine-Derived Fungi}

In order to evaluate cytotoxicity of the extracts from marine-derived fungi in RAW 264.7 cells, cell viabilities were estimated via an MTT assay, which is a test of metabolic competence predicated upon the assessment of mitochondrial performance. As shown in Figure 1, the cells treated with LPS showed $87 \%$ cell viability, and some extracts showed strong cytotoxicity in RAW 264.7 cell. Especially, BE and ME of the unidentified strains of 003-2 and 007-1, as well as P. chrysogenum (010-1), P. janthinellum (053-1), Penicillium sp. (079-1), P. chrysogenum (079-2), Penicillium sp. (079-3) and the BE of A. clavatus (045-3), F. oxysporum (069-), the ME of Fusarium sp. (050-1), P. crustosum (066-2) showed lower cell viabilities than those of other extracts. However, the BE of E. amstelodami (015-2), E. amstelodami (045-1) and ME of P. oxalicum (075-1) showed slight cytotoxicities in RAW 264.7 cells. From the result it is very clearly proved that $E$. amstelodami is relatively non-toxic and can release non-toxic substances.

In order to evaluate the potential anti-inflammatory effects of the extracts with the protective effect against NO production in RAW 264.7 cells, the cells were treated with the extracts for $1 \mathrm{~h}$ and then treated with LPS $(1 \mu \mathrm{g} / \mathrm{mL})$ for $24 \mathrm{~h}$. NO concentrations were measured in the culture supernatants by the Griess reaction and ELISA assay. The LPS treatment significantly increased the production of NO. However, the BE of E. amstelodami (015-2), E. amstelodami (045-1), Aspergillus sp. (063-3) and P. oxalicum (075-1) and ME of A. clavatus (045-3), F. oxysporum (069-1) showed significant inhibitory effects against NO production without cytotoxicity at concentration of $200 \mu \mathrm{g} / \mathrm{mL}$. Especially, the BE of E. amstelodami (015-2), E. amstelodami (045-1), and P. oxalicum (075-1) showed the highest inhibitory activities for NO production with $60.4 \%, 52.9 \%$, and $57.6 \%$ respectively (Figure 2). Therefore, these marine-derived fungi may produce anti-inflammatory substances. 


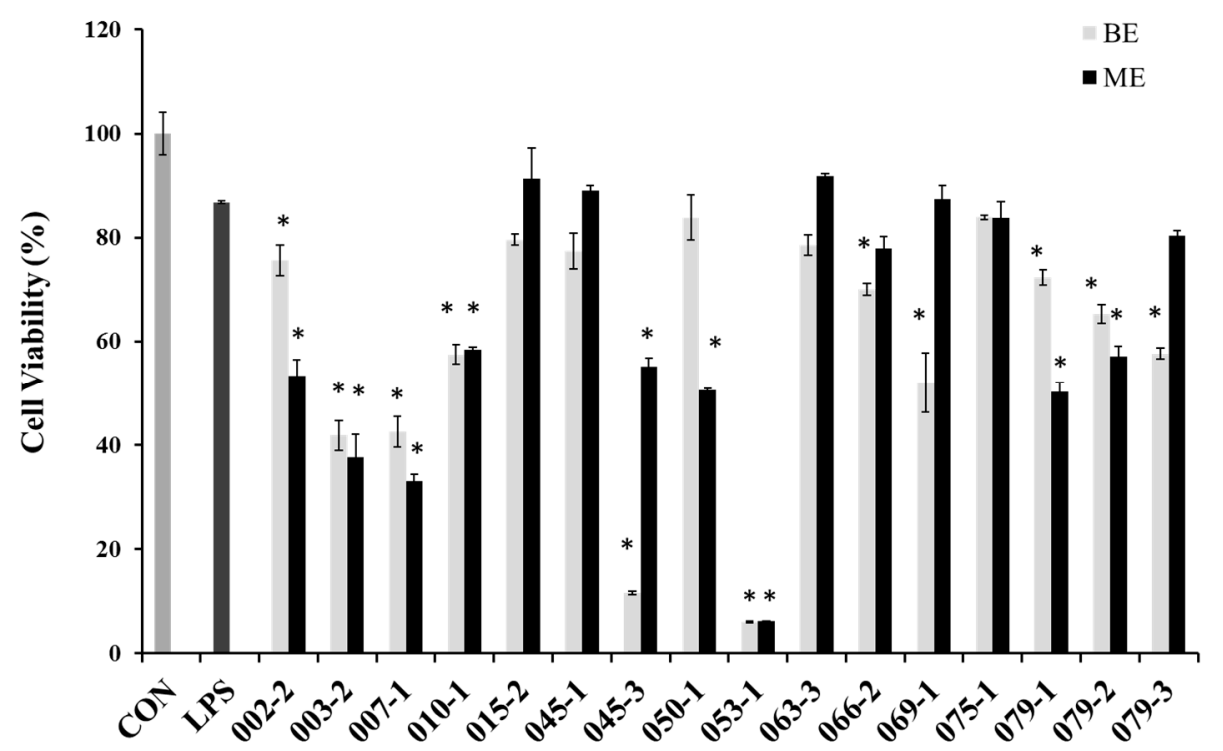

Figure 1. Cell viability of the extracts from marine-derived fungi in RAW 264.7 macrophages. Experiments were performed in triplicate and the data are expressed as mean $\pm \mathrm{SE}$. BE and ME represent the broth and mycelium extract obtained from each of the cultured fungus. ${ }^{*} p<0.05$ indicates significant differences from the LPS-stimulated group.

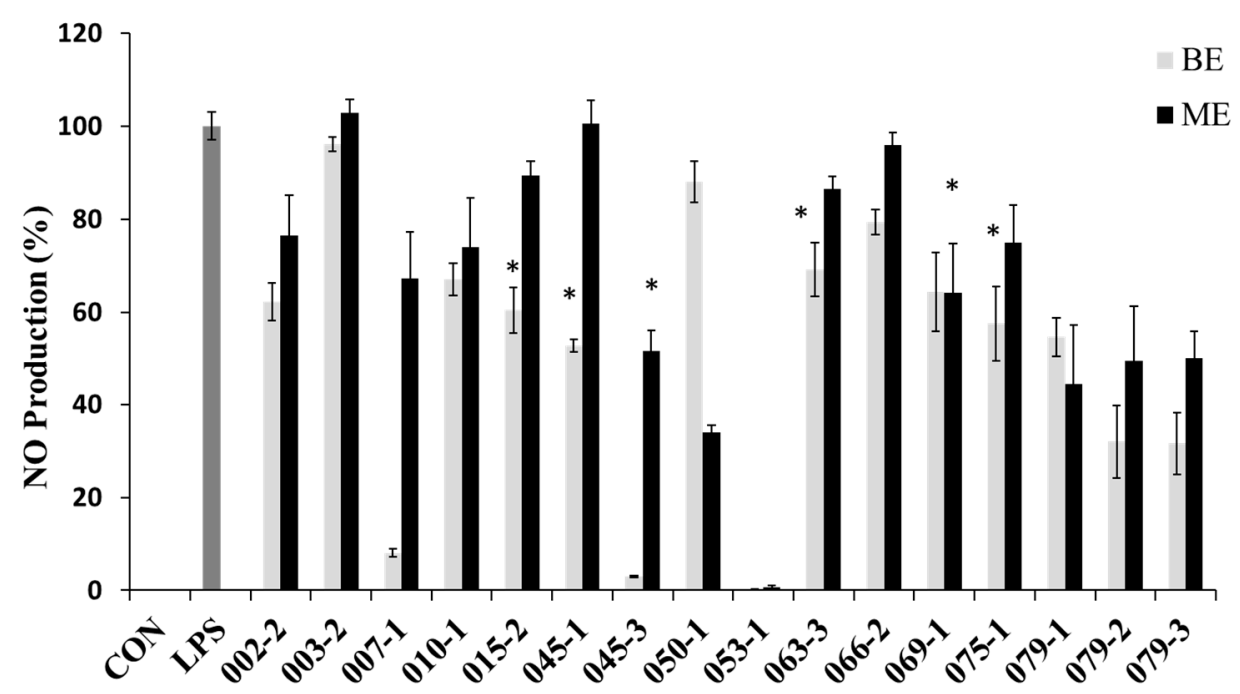

Figure 2. Nitric oxide (NO) production inhibitory effects of the extracts from marine-derived fungi. Each value indicates the mean \pm S.D. and is representative of results obtained from three independent experiment. ${ }^{*} p<0.05$ indicates significant differences from the LPS-stimulated group.

\subsection{Isolation and Identification of Bioactive Natural Products from E. Amstelodami}

The strain, E. amstelodami (015-2) was selected for the further anti-inflammatory effects, therefore it was cultured for $30 \mathrm{~d}$ (static) at $29^{\circ} \mathrm{C}$ in SWS medium. The broth and mycelium were separated by filtration. Its BE possessed higher NO production inhibitory activity than ME. Then, BE was purified using silica column chromatography followed by Sephadex LH-20 chromatography. Three compounds have been successfully isolated. The structures were identified by analyses of the MS and NMR data as well as comparison of those data with the previous reports.

Asperflavin (Figure 3 (1)): greenish amorphous powder, ESI-MS $m / z: 287[\mathrm{M}-\mathrm{H}]^{-} .{ }^{1} \mathrm{H}-\mathrm{NMR}$ (DMSO- $\left.d_{6}, 400 \mathrm{MHz}\right): \delta 6.78$ (1H, s, H-10), $6.54(1 \mathrm{H}, \mathrm{d}, J=2.0, \mathrm{H}-5), 6.42(1 \mathrm{H}, \mathrm{d}, J=2.0, \mathrm{H}-7), 3.84(3 \mathrm{H}$, 
s, CH3O-8), $2.95(2 \mathrm{H}, \mathrm{s}, \mathrm{H}-4), 2.85(1 \mathrm{H}, \mathrm{d}, J=16.9, \mathrm{H}-2 \mathrm{a}), 2.79(1 \mathrm{H}, \mathrm{d}, J=16.9, \mathrm{H}-2 \mathrm{~b}), 1.26\left(3 \mathrm{H}, \mathrm{s}, \mathrm{CH}_{3}-3\right)$. ${ }^{13} \mathrm{C}$ NMR (DMSO- $d_{6}, 100 \mathrm{MHz}$ ): $\delta 203.2$ (C-1), 165.0 (C-9), 161.2 (C-8), 160.6 (C-6), 141.6 (C-10a), 137.8 (C-4a), 115.7 (C-10), 108.8 (C-8a), 108.1 (C-9a), 101.9 (C-5), 97.8 (C-7), 69.4 (C-3), 55.7 (CH3O-8), 51.5 (C-2), 42.7 (C-4), 28.9 (CH3-3).

Asperflavin (Figure 3 (1)) was isolated as greenish amorphous powder. The LR-ESIMS data give a molecular ion peak at $m / z 287[\mathrm{M}-\mathrm{H}]^{-}$. The molecular formula of the compound was determined as $\mathrm{C}_{16} \mathrm{H}_{16} \mathrm{O}_{5}$ base on the MS and NMR data. The ${ }^{1} \mathrm{H}$ and ${ }^{13} \mathrm{C}-\mathrm{NMR}$ data showed the presence of a carbonyl, a methoxyl, a methyl, two aliphatic methylenes, three aromatic protons among which two were meta-coupled with each other, an aliphatic quaternary carbon bearing oxygen, seven aromatic quaternary carbons among which three were bearing oxygen in the compound. It was determined as asperflavin as comparison with the previous report $[19,20]$.

Neoechinulin A (Figure 3 (2)): white powder. ESI-MS $m / z: 324[\mathrm{M}+\mathrm{H}]^{+},{ }^{1} \mathrm{H}-\mathrm{NMR}$ (DMSO- $d_{6}$, $400 \mathrm{MHz}): \delta 1.38(3 \mathrm{H}, \mathrm{d}, J=6.8, \mathrm{H}-12), 1.47\left(6 \mathrm{H}, \mathrm{s}, \mathrm{CH}_{3}-18 / 19\right), 4.16(1 \mathrm{H}, \mathrm{qd}, J=7.2,1.6, \mathrm{H}-12), 5.01(1 \mathrm{H}$, d, $J=13.1$, Ha-17), 5.05 (1H, d, J = 6.2, Hb-17), 6.07 (1H, dd, $J=13.1,6.2, \mathrm{H}-16), 6.89$ (1H, s, H-14), 7.01 $(1 \mathrm{H}, \mathrm{dd}, J=7.6,7.3, \mathrm{H}-6), 7.08(1 \mathrm{H}, \mathrm{dd}, J=7.8,7.6, \mathrm{H}-5), 7.19(1 \mathrm{H}, \mathrm{d}, J=7.8, \mathrm{H}-4), 7.42(1 \mathrm{H}, \mathrm{d}, J=7.3$, H-7), 8.32 (1H, s, H-8), ${ }^{13}$ C-NMR (DMSO-d $d_{6}, 100$ MHz): $\delta 166.4$ (C-13), 159.9 (C-10), 145.1 (C-16), 143.9 (C-2), 135.1 (C-7a), 125.9 (C-3a), 124.9 (C-9), 120.7 (C-6), 119.3 (C-5), 118.8 (C-4), 111.6 (C-8), 111.5 (C-7), 110.1 (C-17), 103.4 (C-3), 50.5 (C-12), 38.9 (C-15), 27.5 (C-18/19), 19.6 (C-20).

Neoechinulin A (Figure 3 (2)), a white powder, has a molecular ion peak at $m / z 322[\mathrm{M}-\mathrm{H}]^{-}$. The molecular formula of the compound was determined as $\mathrm{C}_{19} \mathrm{H}_{21} \mathrm{~N}_{3} \mathrm{O}_{2}$ base on the MS and NMR data. It was identified as neoechinulin A, which was previously isolated from fungal genera Eurotium and Apsergillus [21].

Preechinulin (Figure 3 (3)): white powder. ESI-MS $m / z: 326[\mathrm{M}+\mathrm{H}]^{+},{ }^{1} \mathrm{H}-\mathrm{NMR}$ (DMSO- $d_{6}, 400 \mathrm{MHz}$ ): $\delta 1.23(3 \mathrm{H}, \mathrm{d}, J=7.1, \mathrm{H}-20), 1.49\left(6 \mathrm{H}, \mathrm{s}, \mathrm{CH}_{3}-18 / 19\right), 3.07(1 \mathrm{H}, \mathrm{dd}, J=9.0,14.4, \mathrm{Ha}-8), 3.36(1 \mathrm{H}, \mathrm{d}, J=4.6$, Hb-8), 3.79 (1H, qd, J = 2.5, 7.0, H-12), 3.96 (1H, m, H-9), 5.04 (2H, d, J = 17.6, H-17), $6.18(1 \mathrm{H}, \mathrm{dd}$, $J=10.5,17.4, \mathrm{H}-16), 6.93(1 \mathrm{H}, \mathrm{dd}, J=7.3,7.5, \mathrm{H}-5), 7.02(1 \mathrm{H}, \mathrm{dd}, J=7.7,7.3, \mathrm{H}-6), 7.31(1 \mathrm{H}, \mathrm{d}, J=7.5$, H-4), $7.42(1 \mathrm{H}, \mathrm{d}, J=7.7, \mathrm{H}-7), 7.49(1 \mathrm{H}, \mathrm{d}, J=2.9, \mathrm{NH}-14), 8.16(1 \mathrm{H}, \mathrm{d}, J=2.5, \mathrm{NH}-11), 10.5(1 \mathrm{H}, \mathrm{s}$, NH-1). ${ }^{13}$ C-NMR (DMSO- $d_{6}, 100$ MHz): $\delta 167.8$ (C-13), 167.3 (C-10), 146.5 (C-16), 141.3 (C-2), 134.9 (C-7a), 128.9 (C-3a), 120.5 (C-6), 118.3 (C-5), 117.9 (C-4), 111.0 (C-17), 110.1 (C-7), 104.6 (C-3), 55.7 (C-9), 50.3 (C-12), 31.0 (C-8), 28.0 (C-19), 27.9 (C-18), 20.6 (C-20).

Preechinulin (Figure $3(3)$ ), a white powder, showed a molecular ion peak at $m / z 326[\mathrm{M}+\mathrm{H}]^{+}$. The molecular formula of the compound was determined as $\mathrm{C}_{19} \mathrm{H}_{23} \mathrm{~N}_{3} \mathrm{O}_{2}$ base on the MS and NMR data. The structure of preechinulin was elucidated by analysis of its $1 \mathrm{H}, 13 \mathrm{C}-\mathrm{NMR}$ and MS data, as well as by comparison of its spectral data to those reports in the literature [22].<smiles>COc1cc(O)cc2cc3c(c(O)c12)C(=O)C[C@](C)(O)C3</smiles>

1

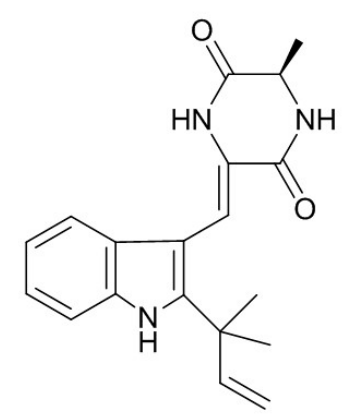

2

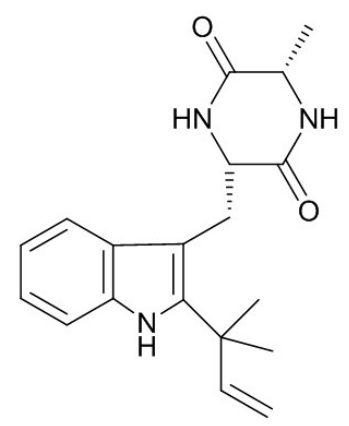

3

Figure 3. Chemical structures of three isolated compounds from marine-derived fungus, E. amstelodami. 


\subsection{Cell Viability of the Isolated Compounds in Raw 264.7 Cells}

To investigate the cytotoxic effects of the isolated compounds in RAW 264.7 cells in the presence of LPS $(1 \mu \mathrm{g} / \mathrm{mL})$, MTT assays were employed. As shown in Figure 4 , when the cells were treated with asperflavin at all the concentrations used in the study along with LPS, no significant differences in the cell viability were found, however, neoechinulin A and preechinulin indicated cytotoxic effects in RAW 264.7 cells. Thus, asperflavin was used for further experiments.

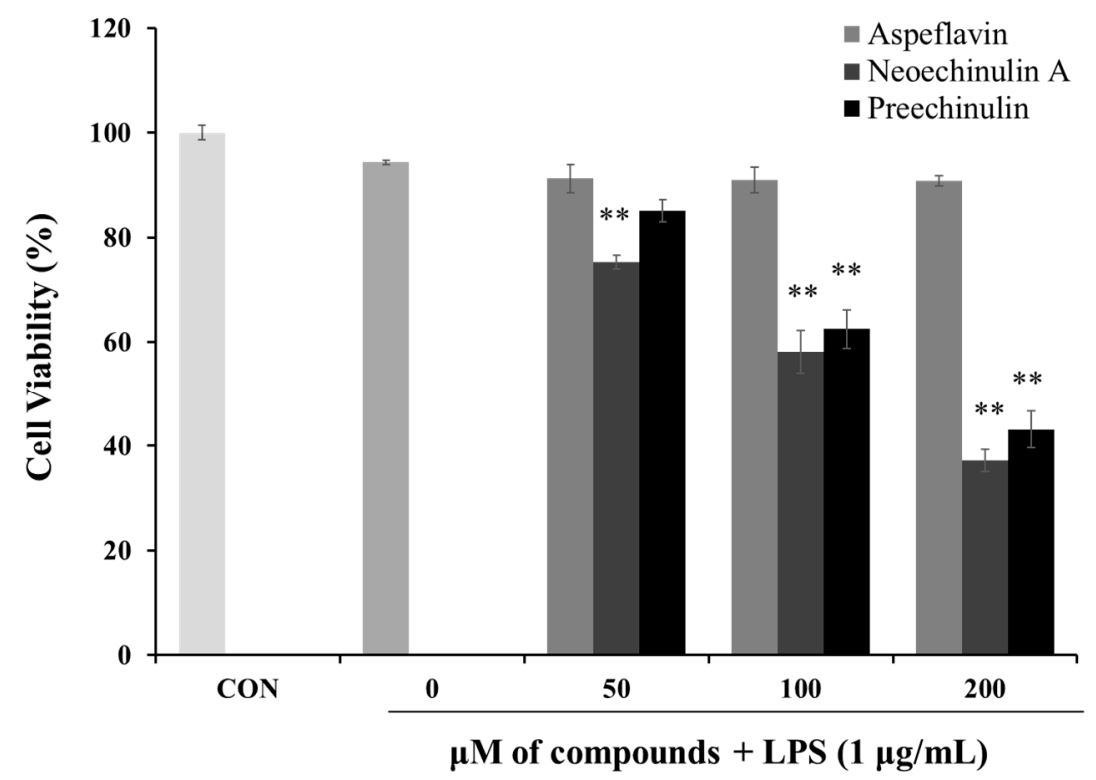

Figure 4. Cytotoxicities of asperflavin, neoechinulin A and preechinulin on cell viability in LPS-stimulated RAW 264.7 cells. RAW 264.7 cells were cultured with the different concentrations (50, 100 , and $200 \mu \mathrm{M})$ of the compounds and LPS $(1 \mu \mathrm{g} / \mathrm{mL})$ for $24 \mathrm{~h}$. Each value indicates the mean \pm S.D. and is representative of results obtained from three independent experiment. ${ }^{* *} p<0.01$ indicates significant differences from the LPS-stimulated group.

\subsection{Effects of Asperflavin on NO and PGE 2 Production in LPS-Treated RAW 264.7 Cells}

The inhibitory effect of asperflavin on NO production in RAW 264.7 cells was evaluated and showed in the Figure 5A. Asperflavin could significantly inhibit LPS-induced NO production in a concentration-dependent manner and showed NO production of $58.5 \%, 41.4 \%$, and $4.6 \%$ at the concentrations of 50,100 and $200 \mu \mathrm{M}$, respectively.

The potential effects of asperflavin on the inhibition of $\mathrm{PGE}_{2}$ production were examined and shown in Figure 5B. Asperflavin could significantly inhibit LPS-induced PGE $_{2}$ production in a concentration-dependent manner, except for the treatment at $50 \mu \mathrm{M}$ of asperflavin. In the asperflavin-treated groups, the $\mathrm{PGE}_{2}$ production were $87.6 \%$, and $55.9 \%$ at the concentrations of 100 and $200 \mu \mathrm{M}$, respectively.

\subsection{Effects of Asperflavin on Expression of iNOS and COX-2 Protein in LPS-Stimulated RAW 264.7 Cells}

In order to understand the mechanism by which asperflavin reduces LPS-induced NO and $\mathrm{PGE}_{2}$ production, we investigated the ability of asperflavin on expression of iNOS and COX-2 in LPS-stimulated RAW 264.7 cells. As shown in Figure 6, the treatment of LPS $(1 \mu \mathrm{g} / \mathrm{mL})$ could significantly increase the expression levels of iNOS and COX-2 compared to the control without LPS, but asperflavin inhibited the expression of iNOS in a dose-dependent manner. On the other hand, the expression of COX-2 was not decreased by treatment of asperflavin at all the concentrations. 
A

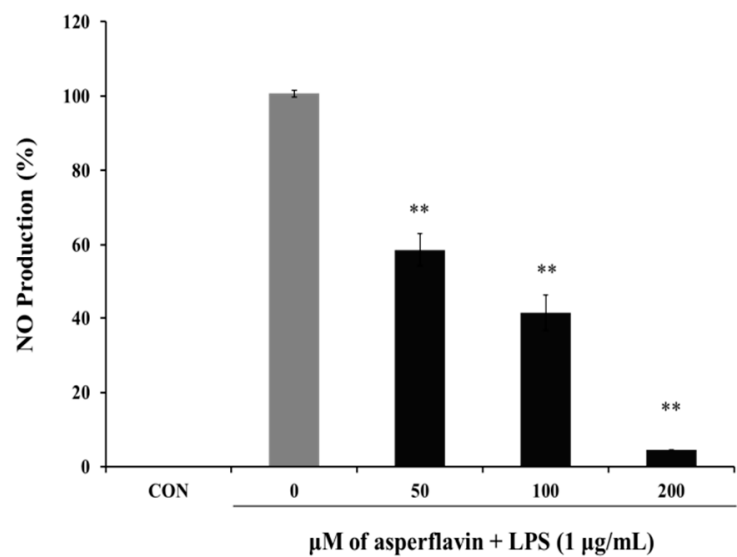

B

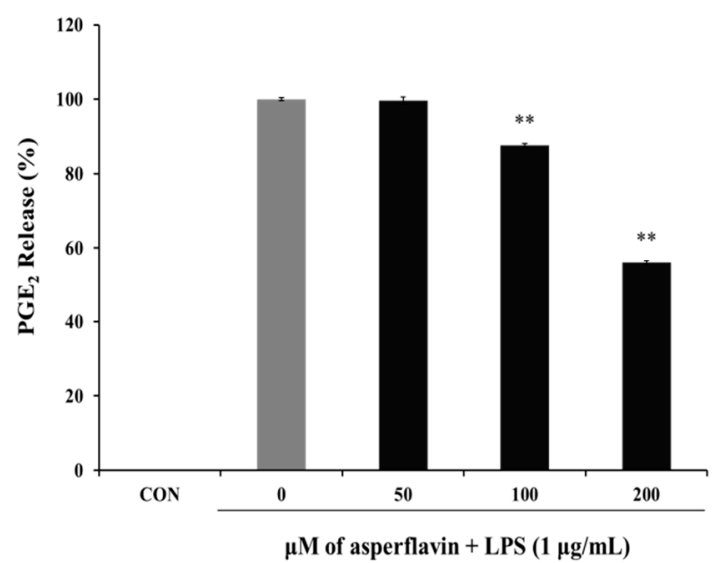

Figure 5. Inhibitory effect of asperflavin on $\mathrm{NO}(\mathbf{A})$ and $\mathrm{PGE}_{2}(\mathbf{B})$ production in LPS-stimulated RAW 264.7 cells. Cells $\left(1 \times 10^{5}\right.$ cells $\left./ \mathrm{mL}\right)$ were stimulated by LPS $(1 \mu \mathrm{g} / \mathrm{mL})$ for $24 \mathrm{~h}$ in the presence of asperflavin $(50,100$, and $200 \mu \mathrm{M})$. The NO production was assayed in the culture medium and the $\mathrm{PGE}_{2}$ production in the supernatants was determined by ELISA. Each value indicates the mean \pm S.D. and is representative of results obtained from three independent experiment. ${ }^{* *} p<0.01$ indicates significant differences from the LPS-stimulated group.

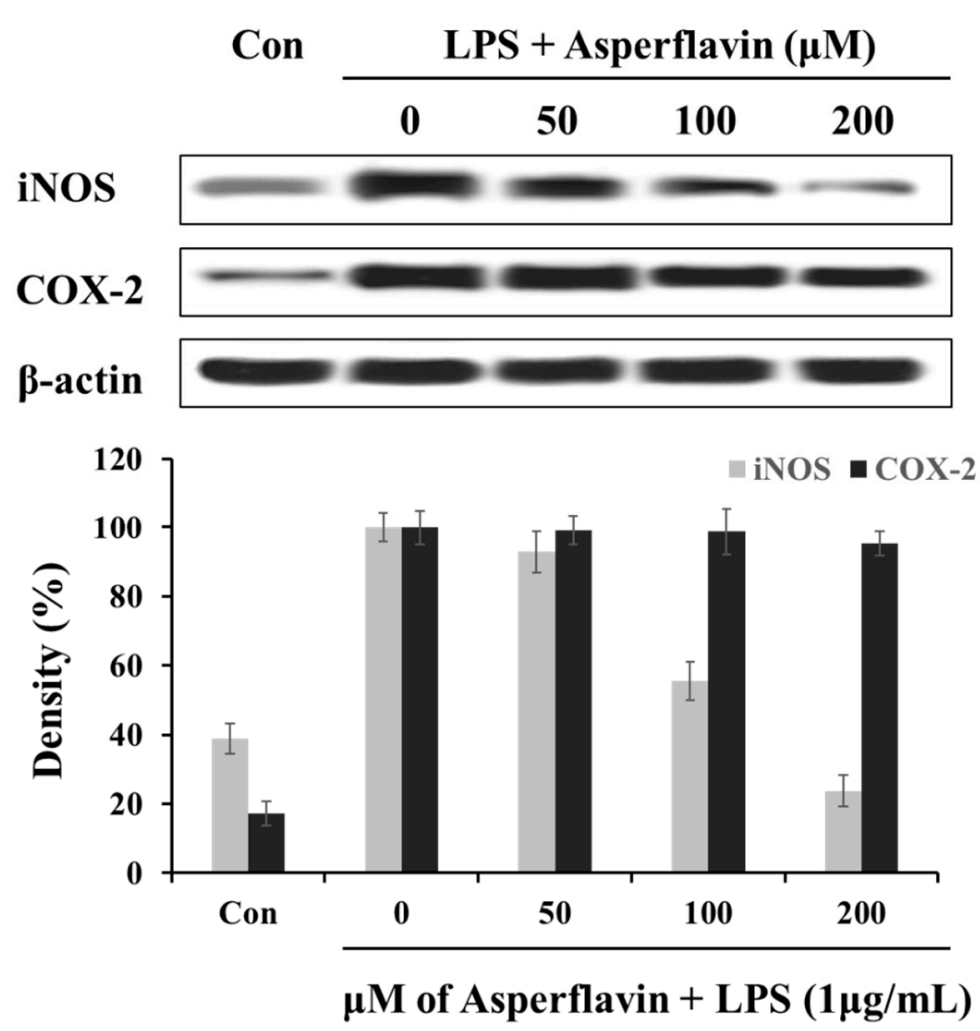

Figure 6. Inhibitory effects of asperflavin on the expression of iNOS and COX-2 in LPS-stimulated RAW 264.7 cells. The RAW 264.7 cells were pre-incubated for $18 \mathrm{~h}$, and stimulated with LPS $(1 \mu \mathrm{g} / \mathrm{mL})$ for $24 \mathrm{~h}$ in the presence of asperflavin $(50,100$, and $200 \mu \mathrm{M})$. The expression levels of iNOS and COX-2 were determined using immunoblotting method. 

264.7 Cells

The release of pro-inflammatory cytokines is an important mechanism by which the immune cells regulate the inflammatory responses and contribute to various inflammatory and autoimmune disorders. Therefore, we examined the effects of asperflavin on LPS-induced TNF- $\alpha$, IL-1 $\beta$, and IL- 6 production using ELISA kit. LPS could induce a significant increase of cytokines including TNF- $\alpha$ (Figure 7A), IL-1 $\beta$ (Figure 7B) and IL-6 (Figure 7C) compared to the control group. However, pre-treatment with asperflavin significantly reduced the productions of all the pro-inflammatory cytokines at the concentrations of $200 \mu \mathrm{M}$. At the other lower concentrations of 50 and $100 \mu \mathrm{M}$, the levels of TNF- $\alpha$ were significantly reduced, but no significant reductions of IL-1 $\beta$ were observed. The production of IL-6 in the asperflavin-treated group at the concentration of $50 \mu \mathrm{M}$ was no significant different compared with LPS-treated group.

A

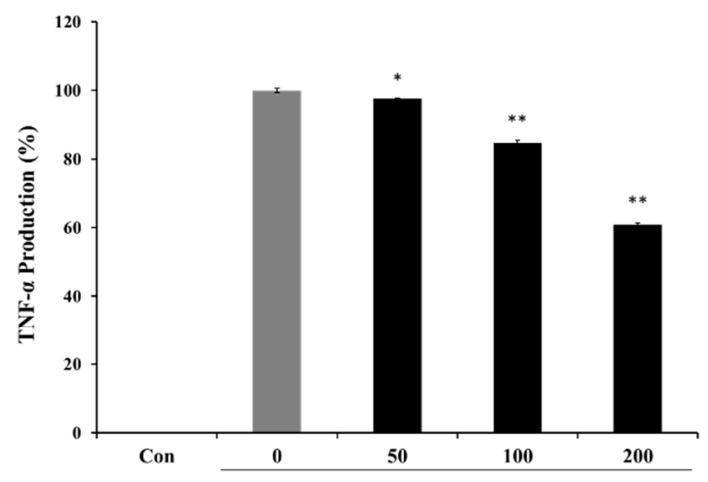

C

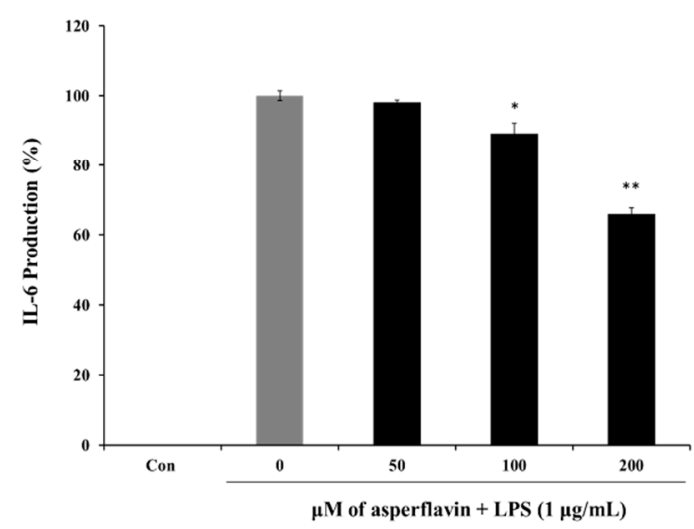

B

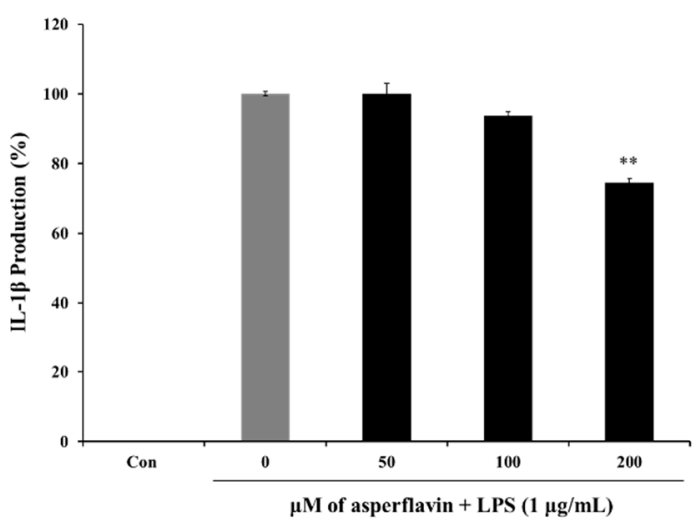

$\mu \mathrm{M}$ of asperflavin $+\mathrm{LPS}(1 \mu \mathrm{g} / \mathrm{mL})$

Figure 7. Inhibitory effects of asperflavin on TNF- $\alpha$ (A); IL-1 $\beta$ (B) and IL-6 (C) production in LPS-stimulated RAW 264.7 cells. The production of TNF- $\alpha$ was assayed in the culture medium of cells stimulated by LPS $(1 \mu \mathrm{g} / \mathrm{mL})$ for $24 \mathrm{~h}$ in the presence of asperflavin $(50,100$, and $200 \mu \mathrm{M})$. Supernatants were collected, and the TNF- $\alpha$, IL- $1 \beta$ and IL- 6 production in the supernatants were determined by ELISA. Each value indicates the mean \pm S.D. and is representative of results obtained from three independent experiment. ${ }^{*} p<0.05$ and ${ }^{* *} p<0.01$ indicate significant differences from the LPS-stimulated group.

\section{Discussion}

Marine microorganisms are recognized as important sources of pharmacologically active metabolites [23]. In particular, marine-derived fungi have proven to be a promising source of structurally novel and biologically active secondary metabolites [24,25]. In this study, the 16 fungal strains have been isolated and belong to the genus of Penicillium, Aspergillus, Eurotium, 
and Fusarium. According to the results of cell viability and NO production of BE and ME from the marine fungi in LPS-treated RAW 264.7 cells, the BE of Eurotium amstelodami (015-2), Eurotium amstelodami (045-1), and Penicillium oxalicum (075-1) showed significant NO production inhibitory effects without cytotoxicity. Thus, the fungal strains could be good sources for biological natural products. In particular, E. amstelodami (015-2) was selected as our target strain for further studies. Previously, E. amstelodami was isolated from intermediate- or low-moisture food and in or near building air samples [26-28]. Slack also reported that the major secondary metabolites of $E$. amstelodami were neoechinulin A, neoechinulin B, epiheveadride, flavoglaucin, auroglaucin, and isotetrahydroauroglaucin [28]. Interestingly, this strain was found that it could growth well in the marine environment in our study.

Although natural products isolated from marine-derived fungi have been reported to possess various biological activity, the research focusing on their anti-inflammatory activity is few. Penstyrylpyrone, a new styrylpyrone-type metabolite isolated from marine-derived fungus Penicillium sp. was found to inhibit PTP1B activity and reduce NO, PGE 2 , TNF- $\alpha$ and IL-1 $\beta$ production through NF-kB pathway as well as expression of anti-inflammatory HO-1 [29]. Penicillinolide A, a new 10-membered lactone isolated from Penicillium sp., could suppressed the production of pro-inflammatory mediators via inhibition of the NF-kB pathway [30]. Shin reported a new tazawaic acid derivative, tanzawaic acid $Q$, together with four known compounds. The new compound was found to inhibit LPS-induced NO and PGE2 production via suppression of the expression of iNOS and COX-2 proteins in RAW264.7 cells [31].

As the result, three compounds, asperflavin, neochinulin A and preechinulin were successfully isolated from BE of E. amstelodami. Neoechinulin A has been demonstrated to have various biological activities, such as anti-tumor, anti-oxidant, and pro-inlfammatory activities. The study of Kim et al. indicated that neoechinulin A could suppress the production of pro-inflammatory mediators, and cytokines in LPS-induced RAW264.7 macrophages. The potential mechanism of its anti-inflammatory activity was due to the inhibition of NF- $\mathrm{B}$ B and p38 MAPK pathways [32]. However, in our study, neochinulin A and preechinulin has shown the significant cytotoxicity in RAW264.7 cells at the concentration of 50 to $200 \mu \mathrm{M}$. Asperflavin was initially isolated from entomogenous strain of Aspergillus flavus. It was also found in the marine-derived fungi of Eurotium rubrum, Eurotium repens, Eurotium cristatum and the fungus of Eurotium herbariorum which was used in the process of manufacturing karebushi (a katsuobushi) [33-35]. However, there are few reports to date on the biological activity of asperflavin. In this study, asperflavin indicated no-toxicity up to the concentration of $200 \mu \mathrm{M}$. Asperflavin significantly inhibited the LPS-induced NO and PGE 2 production but the expression of iNOS was only significantly suppressed, not COX-2. Therefore asperflavin might go through the pathway of iNOS inhibition. Additionally, asperflavin significantly inhibited the production of pro-inflammatory cytokines, TNF- $\alpha$, IL- $1 \beta$ and IL- 6 in the LPS-stimulated RAW 264.7 macrophages.

\section{Materials and Methods}

\subsection{Chemicals and Materials}

Column chromatography were carried out by Silica Gel 60 (230-400 mesh, Merck, Darmstadt, Germany), ODS (12 nm, YMC, Kyoto, Japan), Sephadex LH-20 (Sigma, St. Louis, MO, USA). Thin-layer chromatography (TLC) was run on pre-coated Merck Kieselgel 60 F254 plates (0.25 mm). 3-(4,5-dimethylthiazol-2-yl)-2,5-diphenylte-trazolium bromide (MTT) and lipopolysaccharide (LPS) were purchased from Sigma Chemical Co. (St. Louis, MO, USA). Dulbecco's modified Eagile's medium (DMEM), fetal bovine serum (FBS), penicillin-streptomycin and trypsine-EDTA were purchased from Gibco/BRL (Grand Island, NY, USA). The enzyme-linked immunosorbent assay (ELISA) kit for IL-1 $\beta$, IL-6, TNF- $\alpha$ and Prostaglandin $\mathrm{E}_{2}\left(\mathrm{PGE}_{2}\right)$ were purchased from R\&D systems Inc (Minneapolis, MN, USA). Antibodies against iNOS and COX-2 were obtained from Calbiochem (La Jolla, CA, USA) and 
BD Biosciences Pharmingen (San Jose, CA, USA, respectively). All of the solvent and chemicals used in this study were of reagent grades from commercial sources.

\subsection{Fungus Strain}

There were 16 fungal strains isolated from the marine-derived samples including algae, float, animal and drift wood collected from the coast of Jeju Island, Korea. The isolated marine-derived fungi were identified according to a molecular biological protocol by DNA amplification and sequencing of ITS region (Table 1). The voucher specimens are deposited at Jeju National University.

For evaluation of the biological activities of the extracts from the fungal strains, all the strains were cultured in the flask with $100 \mathrm{~mL}$ of liquid culture medium. After several days, the cultured fungus was filtered through cheese-cloth to separate into broth and mycelium. The broth was extracted with EtOAc, and the EtOAc solution was concentrated under a reduced pressure to give a broth extract (BE). The mycelium was freeze-dried and extracted three times with $\mathrm{CHCl}_{3}-\mathrm{MeOH}$ (1:1) for $2 \mathrm{~h}$ using sonication and gave a mycelium extract (ME). The samples of BE and $\mathrm{ME}$ from each strain were checked by TLC to observe the profile of chemical composition (date not shown). All the extracts were prepared with different solvents for determination of cell viability and NO production in RAW264.7 cells.

\subsection{Extraction and Isolation of Active Compounds from E. Amstelodami}

According to the results of MTT and NO production assays, the strain, E. amstelodami (015-2) was selected as the target strain for the isolation of nature products and evaluation of their anti-inflammatory activity. The fugal strain was cultured $(8 \mathrm{~L})$ for $30 \mathrm{~d}$ (static) at $29{ }^{\circ} \mathrm{C}$ in SWS medium containing of soytone $(0.1 \%)$, soluble starch $(1.0 \%)$ and seawater $(100 \%)$. The BE were prepared according to the above methods $(015-2 \mathrm{~B})(0.7 \mathrm{~g})$. The BE $(0.7 \mathrm{~g})$ which showed higher inhibitory effect against NO production was subjected to silica gel flash chromatography (n-hexane/EtOAc, EtOAc/MeOH) to furnish twelve fractions (Fr. B1-B12) on the basis of TLC analysis. Fr. B7 (161.2 mg) was further purified by Sephadex LH-20 column eluting with $\mathrm{MeOH}$ to give crude compound 1 and compound 2. Final purification of each crude compound by HPLC (Sunfire, Waters, 50\% $\mathrm{MeOH}$ ) yielded the compound 1 (25.2 mg) and 2 (35.6 mg). Fr. B10 (130.5 mg) was further purified by Sephadex LH-20 column eluting with $\mathrm{MeOH}$ to give crude compound 3. Then, the fraction was finally purified by ODS column to afford compound 3 (4.6 mg).

The ${ }^{1} \mathrm{H}-\mathrm{NMR}$ and ${ }^{13} \mathrm{C}-\mathrm{NMR}$ spectra of the isolated compounds were recorded on a JEOL JNM-ECP $400 \mathrm{MHz}$ NMR spectrometer, using DMSO- $d_{6}$ solvent peak (2.50 ppm in ${ }^{1} \mathrm{H}$ and $39.5 \mathrm{ppm}$ in $\left.{ }^{13} \mathrm{C}-\mathrm{NMR}\right)$ as an internal reference standard. MS spectra were obtained on a JEOL JMS-700 spectrometer.

\subsection{Cell Culture}

The murine macrophage cell line RAW 264.7 was purchased from the Korean Cell Line Bank (KCLB, Seoul, Korea). RAW 264.7 cells were cultured in DMEM supplemented with $100 \mathrm{U} / \mathrm{mL}$ of penicillin, $100 \mu \mathrm{g} / \mathrm{mL}$ of streptomycin and 10\% FBS. The cells were incubated in an atmosphere of $5 \%$ $\mathrm{CO}_{2}$ at $37^{\circ} \mathrm{C}$ and were sub-cultured every 3 days.

\subsection{MTT Assay}

MTT assay was adopted for evaluation of cytotoxicity. The RAW 264.7 cells were seeded in 96-well plate at a concentration of $5 \times 10^{5}$ cells $/ \mathrm{ml}(180 \mu \mathrm{L})$. After $24 \mathrm{~h}$ incubation at $37^{\circ} \mathrm{C}$ under a humidified atmosphere, the cells were treated with $10 \mu \mathrm{L}$ of the extracts of sixteen fungi $(200 \mu \mathrm{g} / \mathrm{mL})$ or the isolated compounds at the concentration of 50,100 and $200 \mu \mathrm{M}$, and further incubated for $30 \mathrm{~min}$. The $50 \mu \mathrm{L}$ of MTT stock solution $(2 \mathrm{mg} / \mathrm{mL}$ ) was then applied to the wells, to a total reaction volume of $250 \mu \mathrm{L}$. After $24 \mathrm{~h}$ of incubation, the plates were centrifuged for $5 \mathrm{~min}$ at $800 \times g$, and the supernatants were aspirated. The formazan crystals in each well were dissolved in $150 \mu \mathrm{L}$ of dimethyl sulfoxide (DMSO), and the absorbance was measured via ELISA at a wavelength of $540 \mathrm{~nm}$. The percentage inhibitory effect was evaluated in accordance with the quantity of MTT converted to the insoluble 
formazan salt. The optical density of the formazan generated in the control cells was considered to represent $100 \%$ viability. The data are expressed as mean percentages of the viable cells versus the respective control.

\subsection{Determination of NO Production}

RAW 264.7 cells $\left(5 \times 10^{5}\right)$ were plated and incubated with the extracts $(200 \mu \mathrm{g} / \mathrm{mL})$ and the compounds at the concentrations of 50,100 and $200 \mu \mathrm{M}$ in the absence or presence of LPS $(1 \mu \mathrm{g} / \mathrm{mL})$ for $24 \mathrm{~h}$. The nitrite concentration in the culture medium was measured as an indicator of NO production, according to the Griess reaction. One hundred microliters of the culture supernatant were mixed with the same volume of Griess reagent $(0.1 \%$ naphtylethylenediamine dihydrochloride and $1 \%$ sulfanilamide in $5 \% \mathrm{H}_{3} \mathrm{PO}_{4}$ ). The absorbance of the mixture was measured with a microplate reader (Ultraspec 2100 pro, Cambridge, UK) at $540 \mathrm{~nm}$. The concentration of nitrite was calculated with sodium nitrite as a standard.

\subsection{Determination of $P G E_{2}$ Production}

RAW 264.7 macrophages were pre-treated with $1 \mathrm{~h}$ with the active compound at the concentrations of 50, 100, $200 \mu \mathrm{M}$ prior to $24 \mathrm{~h}$ of stimulation with LPS $(1 \mu \mathrm{g} / \mathrm{mL})$. The culture supernatants were immediately utilized for $\mathrm{PGE}_{2}$ determination. The $\mathrm{PGE}_{2}$ concentration in the culture medium was quantified using a competitive enzyme immunoassay kit according to the manufacturer's instructions. The production of $\mathrm{PGE}_{2}$ was measured and indicated with comparing to the control treatment.

\subsection{Western Blot Analysis}

RAW 264.7 macrophages were pre-incubated for $24 \mathrm{~h}$, and then stimulated with LPS $(1 \mu \mathrm{g} / \mathrm{mL})$ in the presence of the active compound for the indicated time. After incubation, the cells were collected and washed twice with cold-PBS. The cells were lysed in a lysis buffer [50 mM Tris- $\mathrm{HCl}$ (pH 7.5), $150 \mathrm{mM} \mathrm{NaCl}, 1 \%$ Nonidet P-40, 2 mM EDTA, 1 mM EGTA, $1 \mathrm{mM} \mathrm{NaVO}$, $10 \mathrm{mM} \mathrm{NaF}$, $1 \mathrm{mM}$ dithiothreitol, $1 \mathrm{mM}$ phenylmethylsulfonylfluoride, $25 \mu \mathrm{g} / \mathrm{mL}$ aprotinin, $25 \mu \mathrm{g} / \mathrm{mL}$ leupeptin] and kept on ice for $30 \mathrm{~min}$. Cell lysates were washed by centrifugation, and protein concentrations were determined by using $\mathrm{BCA}^{\mathrm{TM}}$ protein assay kit. Aliquots of the lysates (30-50 $\mu \mathrm{g}$ of protein) were separated on a $12 \%$ SDS-polyacrylamide gel and transferred onto a polyvinylidene fluoride (PVDF) membrane (BIO-RAD, HC, USA) with a glycine transfer buffer [192 mM glycine, $25 \mathrm{mM}$ Tris- $\mathrm{HCl}(\mathrm{pH} 8.8), 20 \% \mathrm{MeOH}(v / v)]$. After blocking the nonspecific site with $1 \%$ bovine serum albumin (BSA), the membrane was then incubated with specific primary antibody at $4{ }^{\circ} \mathrm{C}$ for overnight. The membrane was further incubated for $60 \mathrm{~min}$ with a peroxidase-conjugated secondary antibody (1:5000, Vector Laboratories, Burlingame, CA, USA) at room temperature. The immune-active proteins were detected using an enhanced chemiluminescence (ECL) western blotting detection kit.

\subsection{Measurement of Pro-Inflammatory Cytokines Production}

In order to determine the inhibitory effects of the active compound on production of pro-inflammatory cytokines including TNF- $\alpha$, IL-1 $\beta$ and IL-6, the RAW 264.7 macrophages were incubated with the active compound (50,100 and $200 \mu \mathrm{M})$ in the presence or absence of LPS $(1 \mu \mathrm{g} / \mathrm{mL})$ for $24 \mathrm{~h}$. The inhibitory effects of the compound on the production of pro-inflammatory cytokines in LPS-treated RAW 264.7 cells was determined as described in the Cho et al protocols [36]. Supernatants were used for pro-inflammatory cytokines assay using mouse ELISA kit.

\subsection{Statistical Analysis}

All the data were presented as mean \pm S.D. from three independent experiments unless stated otherwise. Statistical comparisons between different treatments were done by one-way ANOVA with 
Student Newman Keul's post hoc tests using SPSS program (version 19.0). ${ }^{*} p<0.05$, and ${ }^{* *} p<0.01$, vs. LPS-stimulated group.

\section{Conclusions}

In conclusion, we have demonstrated that asperflavin isolated from the marine-derived fungus, E. amstelodami, inhibited the production of $\mathrm{NO}$ and $\mathrm{PGE}_{2}$ production through suppression of iNOS expression in LPS-stimulated RAW 264.7 macrophages. Asperflavin was also found to inhibit the pro-inflammatory cytokines including TNF- $\alpha$, IL- $1 \beta$ and IL- 6 as well. Therefore, our study suggests that asperflavin might be considered a promising agent for the prevention and therapy of inflammatory disease.

Author Contributions: Xiudong Yang performed the experiments and wrote the paper. Min-Cheol Kang performed the experiment; Yong Li and Eun-A. Kim analyzed the data; Sung-Myung Kang performed a part of the work. The works were designed and supervised by You-Jin Jeon.

Conflicts of Interest: The authors declare no conflict of interest.

\section{References}

1. Lin, X.; Han, L.; Ma, J.; Dong, K.; Wang, X.; Zhong, J.; Mu, Y.; Liu, Y.; Huang, X. Ployketide derivatives from a marine-sponge-associated fungus Pestalotionpsis heterocornis. Phytochemistry 2017, 142, 51-59.

2. Ramos, A.A.; Prata-Sena, M.; Castro-Carvalho, B.; Dethoup, T.; Buttachon, S.; Kijjoa, A.; Rocha, E. Potential of four marine-derived fungi extracts as anti-proliferative and cell death-inducing agents in seven human cancer cell lines. Asian Pac. J. Trop. Med. 2015, 8, 798-806. [CrossRef] [PubMed]

3. Rateb, M.E.; Ebel, R. Secondary metabolites of fungi from marine habitats. Nat. Prod. Rep. 2011, 28, 290-344. [CrossRef] [PubMed]

4. Zhou, H.Y.; Shin, E.M.; Guo, L.Y.; Zou, L.B.; Xu, G.H.; Lee, S.H.; Ze, K.R.; Kim, E.K.; Kang, S.S.; Kim, Y.S. Anti-inflammatory activity of $21(\alpha, \beta)$-methylmelianodiols, novel compounds from Poncirus trifoliata Rafinesque. Eur. J. Pharmacol. 2007, 572, 239-248. [CrossRef] [PubMed]

5. Pierce, G.F. Macrophages: Important physiologic and pathologic sources of polypeptide growth factors. Am. J. Respir. Cell Mol. Biol. 1990, 2, 233-234. [CrossRef] [PubMed]

6. Laskin, D.L.; Pendino, K.J. Macrophages and inflammatory mediators in tissue injury. Annu. Rev. Pharmacol. Toxicol. 1995, 35, 655-677. [CrossRef] [PubMed]

7. Zhou, H.Y.; Shin, E.M.; Guo, L.Y.; Youn, U.J.; Bae, K.H.; Kang, S.S.; Zou, L.B.; Kim, Y.S. Anti-inflammatory activity of 4-methoxyhonokiol is a function of the inhibition of iNOS and COX-2 expression in RAW 264.7 macrophages via NF-KB, JNK and p38 MAPK inactivation. Eur. J. Pharmacol. 2008, 586, 340-349. [CrossRef] [PubMed]

8. Van Snick, J. Interleukin-6: An overview. Annu. Rev. Immunol. 1990, 8, 253-278. [CrossRef] [PubMed]

9. MacMicking, J.; Xie, Q.W.; Nathan, C. Nitric oxide and macrophage function. Annu. Rev. Immunol. 1997, 15, 323-350. [CrossRef] [PubMed]

10. Wang, Q.S.; Cui, Y.L.; Wang, Y.F.; Chi, W. Effects of compounds from Bi-Qi Capsule on the expression of inflammatory mediators in lipopolysaccharide-stimulated RAW 264.7 macrophages. J. Ethnopharmacol. 2011, 136, 480-487. [CrossRef] [PubMed]

11. Becker, S.; Mundandhara, S.; Devlin, R.B.; Madden, M. Regulation of cytokine production in human alveolar macrophages and airway epithelial cells in response to ambient air pollution particles: Further mechanistic studies. Toxicol. Appl. Pharmacol. 2005, 207, 269-275. [CrossRef] [PubMed]

12. Oh, Y.C.; Cho, W.K.; Im, G.Y.; Jeong, Y.H.; Hwang, Y.H.; Liang, C.; Ma, J.Y. Anti-inflammatory effect of Lycium Fruit water extract in lipopolysaccharide-stimulated RAW 264.7 macrophage cells. Int. Immunopharmacol. 2012, 13, 181-189. [CrossRef] [PubMed]

13. Tao, Y.Y.; Zheng, G.H.; Zhao, L.; Wu, J.G.; Zhang, X.Y.; Zhang, S.L.; Huang, Z.J.; Xiong, F.L.; Li, C.M. Anti-inflammatory effects of ethyl acetate fraction from Melilotus suaveolens Ledeb on LPS-stimulated RAW264.7 cells. J. Ethnopharmacol. 2009, 123, 97-105. [CrossRef] [PubMed]

14. Petros, A.; Bennett, D.; Valance, P. Effect of nitric oxide synthase inhibitors on hypotension in patients with septic shock. Lancet 1991, 338, 1557-1558. [CrossRef] 
15. Thiemermann, C. Nitric oxide and septic shock. Gen. Pharmacol. Vasc. Syst. 1997, 29, 159-166. [CrossRef]

16. Picot, D.; Loll, P.J.; Garavito, R.M. The X-ray crystal structure of the membrane protein prostaglandin $\mathrm{H} 2$ synthase-1. Nature 1994, 367, 243-249. [CrossRef] [PubMed]

17. Hawkey, C.J. Cox-2 inhibitors. Lancet 1999, 353, 307-314. [CrossRef]

18. Lee, S.H.; Soyoola, E.; Chanmugam, P.; Hart, S.; Sun, W.; Zhong, H.; Liou, S.; Simmons, D.; Hwang, D. Selective expression of mitogen-inducible cyclooxygenase in macrophages stimulated with lipopolysaccharide. J. Biol. Chem. 1992, 267, 25934-25938. [PubMed]

19. Grove, J.F. New metabolic products of Aspergillus flavus. Part II. Asperflavin, anhydroasperflavin, and 5,7-dihydroxy-4-methylphthalide. J. Chem. Soc. Perkin Trans. 1972, 1, 2406-2411. [CrossRef]

20. Fujimoto, H.; Fujimaki, T.; Okuyama, E.; Yamazaki, M. Immunomodulatory constituents from an ascomycete, Microascus tardifaciens. Chem. Pharm. Bull. 1999, 47, 1426-1432. [CrossRef] [PubMed]

21. Li, Y.; Li, X.; Kim, S.K.; Kang, J.S.; Choi, H.D.; Rho, J.R.; Son, B.W. Golmaenone, a new diketopiperazine alkaloid from the marine-derived fungus Aspergillus sp. Chem. Pharm. Bull. 2004, 52, 375-376. [CrossRef] [PubMed]

22. Hamasaki, T.; Nagayama, K.; Hatsuda, Y. Structure of a new metabolite from Aspergillus chevalieri. Agric. Biol. Chem. 1976, 40, 203-205. [CrossRef]

23. Kim, K.S.; Cui, X.; Lee, D.S.; Ko, W.; Sohn, J.H.; Yim, J.H.; An, R.B.; Kim, Y.C.; Oh, H. Marine fungus Eurotium sp. SF-5989 on inflammatory mediators via the induction of heme oxygenase-1 in lipopolysaccharide-stimulated RAW264.7 macrophages. Int. J. Mol. Sci. 2014, 15, 23749-23765. [CrossRef] [PubMed]

24. Newman, D.J.; Cragg, G.M. Marine-sourced anti-cancer and caner pain control agents in clinical and late preclinical development. Mar. Drugs 2014, 12, 255-278. [CrossRef] [PubMed]

25. Wang, J.F.; Qin, X.; Xu, F.Q.; Zhang, T.; Liao, S.; Lin, X.; Yang, B.; Liu, J.; Wang, L.; Tu, Z.; et al. Tetramic acid derivatives and polyphenols from sponge-derived fungus and their biological evaluation. Nat. Prod. Res. 2015, 29, 1-5. [CrossRef] [PubMed]

26. Beuchat, L.R.; Daza, M.S.T.D. Evaluation of Chemicals for Restricting Colony Spreading by a Xerophilic Mold, Eurotium amstelodami, on Dichloran-18\% Glycerol Agar. Appl. Environ. Microb. 1992, 58, 2093-2095.

27. Antonybabu, S.; Singleton, I. Effects of ozone exposure on the xerophilic fungus, Eurotium amstelodami IS-SAB-01, isolated from naan bread. Int. J. Food Microbiol. 2011, 144, 331-336. [CrossRef] [PubMed]

28. Slack, G.J.; Puniani, E.; Frisvad, J.C.; Samson, R.A.; Miller, J.D. Secondary metabolites from Eurotium species, Aspergillus calidoustus and A. insuetus common in Canadian homes with a review of their chemistry and biological activities. Mycol. Res. 2009, 113, 480-490. [CrossRef] [PubMed]

29. Lee, D.S.; Jang, J.H.; Ko, W.; Kim, K.S.; Sohn, J.H.; Kang, M.S.; Ahn, J.S.; Kim, Y.C.; Oh, H. PTP1B inhibitory and anti-inflammatory effects of secondary metabolites isolated from the marine-derived fungus Penicillium sp. JF-55. Mar. Drugs 2013, 11, 1409-1426. [CrossRef] [PubMed]

30. Lee, D.S.; Ko, W.; Quang, T.H.; Kim, K.S.; Sohn, J.H.; Jang, J.H.; Ahn, J.S.; Kim, Y.C.; Oh, H. Penicillinolide A: A new anti-inflammatory metabolite from the marine fungus Penicillium sp. SF-5292. Mar. Drugs 2013, 11, 4510-4526. [CrossRef] [PubMed]

31. Shin, H.J.; Pil, G.B.; Heo, S.J.; Lee, H.S.; Lee, J.S.; Lee, Y.J.; Lee, J.; Won, H.S. Anti-inflammatory activity of tanzawaic acid derivatives from a marine-derived fungus Penicillium steckii 108YD142. Mar. Drugs 2016, 14, 14. [CrossRef] [PubMed]

32. Kim, K.S.; Cui, X.; Lee, D.S.; Sohn, J.H.; Yim, J.H.; Kim, Y.C.; Oh, H. Anti-inflammatory effect of neoechinulin A from the marine fungus Eurotium sp. SF-5989 through the suppression of NF- $\mathrm{BB}$ and p38 MAPK Pathways in lipopolysaccharide-stimulated RAW264.7 macrophages. Molecules 2013, 18, 13245-13259. [CrossRef] [PubMed]

33. Smetanina, O.F.; Kalinovskii, A.I.; Khudyakova, Y.V.; Slinkina, N.N.; Pivkin, M.V. Kuznetsova, T.A. Metabolites from the marine fungus Eurotium repens. Chem. Nat. Compd. 2007, 43, 395-398. [CrossRef]

34. Du, F.Y.; Li, X.M.; Song, J.Y.; Li, C.S.; Wang, B.G. Anthraquinone derivatives and an orsellinic acid ester from the marine alga-derived endophytic fungus Eurotium cristatum EN-220. Helv. Chim. Acta 2014, 97, 973-978. [CrossRef]

35. Miyake, Y.; Ito, C.; Kimura, T.; Suzuki, A.; Nishida, Y.; Itoigawa, M. Isolation of aromatic compounds produced by Eurotium herbariorum NU-2 from karebushi, a katsuobushi, and their DPPH-radical scavenging activities. Food Sci. Technol. Int. Tokyo 2014, 20, 139-146. [CrossRef] 
36. Cho, J.Y.; Baik, K.U.; Jung, J.H.; Park, M.H. In vitro anti-inflammatory effects of cynaropicrin, a sesquinterpene lactone, from Saussurea lappa. Eur. J. Pharmacol. 2000, 398, 399-407. [CrossRef]

Sample Availability: Three compounds asperflavin, neochinulin A and preechinulin are available from the authors.

(c) 2017 by the authors. Licensee MDPI, Basel, Switzerland. This article is an open access article distributed under the terms and conditions of the Creative Commons Attribution (CC BY) license (http://creativecommons.org/licenses/by/4.0/). 